\title{
PERCEPÇÃO DE ESTUDANTES DA ÁREA DA SAÚDE SOBRE COMUNIDADES RURAIS QUILOMBOLAS NO NORTE DE MINAS GERAIS-BRASIL
}

\section{Students' perception of health on Quilombola Rural Communities in the North of Minas Gerais, Brazil}

\author{
Daniel Antunes Freitas( ${ }^{(1)}$, Géssica Lafetá Rabelo(2), Jéssica Camila Santos Silveira ${ }^{(3)}$, \\ Lucas Ramos Souza ${ }^{(4)}$, Mateus Costa Lima ${ }^{(5)}$, Mayane Moura Pereira ${ }^{(6)}$, Paulo Henrique Tolentino Moura(7), \\ Stéphany Ketllin Mendes Oliveira( ${ }^{(8)}$, Walter dos Reis Siqueira Junior ${ }^{(9)}$, Amaro Sérgio Marques ${ }^{(10)}$, \\ Cláudia Danyella Alves Leão(11), Clayton Paraíso Macedo ${ }^{(12)}$, Antônio Prates Caldeira( ${ }^{(13)}$
}

\section{RESUMO}

Objetivo: verificar a percepção de estudantes da área da saúde sobre as condições de vida e saúde de Comunidades Quilombolas. Método: trata-se de uma pesquisa qualitativa realizada com estudantes da área de saúde que participaram de uma atividade de pesquisa e extensão em Comunidades Rurais Quilombolas do norte de Minas Gerais. Foram usados dados de Diário de Campo de Pesquisa, entrevista feita em grupo focal, e os resultados estudados sob o prisma da Análise de Conteúdo. Resultados: as percepções dos estudantes foram categorizadas em três dimensões: reconhecimento das diferenças culturais, perplexidade com as condições precárias de vida e crescimento pessoal com a experiência. A análise de conteúdo mostrou a importância deste tipo de atividade para estudantes da saúde. Conclusão: o estudo demonstrou a perplexidade dos estudantes quanto aos aspectos de desigualdade que vive as populações quilombolas do norte de Minas Gerais.

DESCRITORES: Vulnerabilidade em Saúde; Saúde Pública; Etnia e Saúde; Brasil

(1) Odontólogo; Professor Orientador do Grupo de Pesquisas Sobre Saúde das Populações Quilombolas do Norte de Minas Gerais - Universidade Estadual de Montes Claros Unimontes; Mestre em Odontologia; Doutorando em Ciências da Saúde pela Unimontes.

(2) Acadêmica do Curso de Medicina da Unimontes; Jovem-Pesquisadora do Grupo de Pesquisas Sobre Saúde das Populações Quilombolas do Norte de Minas Gerais - Universidade Estadual de Montes Claros - Unimontes.

(3) Acadêmica do Curso de Odontologia da SOEBRÁS/ FUNORTE; Jovem-Pesquisadora do Grupo de Pesquisas Sobre Saúde das Populações Quilombolas do Norte de Minas Gerais - Universidade Estadual de Montes Claros - Unimontes.

(4) Acadêmico do Curso de Medicina da Unimontes; Jovem-Pesquisador do Grupo de Pesquisas Sobre Saúde das Populações Quilombolas do Norte de Minas Gerais - Universidade Estadual de Montes Claros - Unimontes.

(5) Acadêmico do Curso de Medicina da Unimontes; Jovem-Pesquisador do Grupo de Pesquisas Sobre Saúde das Populações Quilombolas do Norte de Minas Gerais - Universidade Estadual de Montes Claros - Unimontes.
(6) Odontóloga; Pesquisadora do Grupo de Pesquisas Sobre Saúde das Populações Quilombolas do Norte de Minas Gerais - Universidade Estadual de Montes Claros - Unimontes; Mestranda em Ciências da Saúde pela Unimontes.

(7) Acadêmico do Curso de Medicina da Unimontes; Jovem-Pesquisador do Grupo de Pesquisas Sobre Saúde das Populações Quilombolas do Norte de Minas Gerais - Universidade Estadual de Montes Claros - Unimontes.

(8) Odontóloga; Pesquisadora do Grupo de Pesquisas Sobre Saúde das Populações Quilombolas do Norte de Minas Gerais - Universidade Estadual de Montes Claros - Unimontes; Mestranda em Ciências da Saúde pela Unimontes.

(9) Acadêmico do Curso de Medicina da Unimontes; Jovem-Pesquisador do Grupo de Pesquisas Sobre Saúde das Populações Quilombolas do Norte de Minas Gerais - Universidade Estadual de Montes Claros - Unimontes.

(10) Antropólogo da Saúde; Professor Orientador do Grupo de Pesquisas Sobre Saúde das Populações Quilombolas do Norte de Minas Gerais - Universidade Estadual de Montes Claros - Unimontes ; Mestre em Desenvolvimento Social. 


\section{INTRODUÇÃO}

A população negra formada por grupos remanescentes de escravos africanos, reconhecida como população quilombola, talvez seja o grande emblema do racismo institucional no País. Durante muitos anos essa população foi invisível aos olhos dos gestores governamentais e não recebeu incentivos sociais de qualquer natureza. Em outras palavras, para essa população perpetuou-se uma escravidão de outra natureza, mas igualmente desumana e inaceitável.

As Comunidades Quilombolas foram oficialmente reconhecidas a partir de 1988 e somente passaram a ser consideradas como público-alvo de programas e ações da Assistência Social a partir de $2003 / 2004^{1,2}$. Nessa ocasião, as discriminações étnicas e raciais passaram a ser objeto de enfrentamento da Proteção Social Básica ${ }^{3}$. Políticas específicas na área da saúde também chegaram tardiamente para essa população. $\mathrm{Na}$ análise de Volochko e Batista, esse aspecto não poderia ser diferente e os autores comentam que, em relação ao registro da cor da pele para dados de mortalidade, a informação somente se tornou compulsória em 1996 e para dados de morbidade somente no fim de $2007^{4}$.

O reconhecimento do racismo institucional e da falta de análises mais profundas acerca das iniquidades entre brancos e não brancos ainda não tem resultado em mudanças de comportamento e olhares no âmbito das academias. Para alguns autores, perpetua-se um preconceito sutil e insidioso, que dá força à invisibilidade das comunidades negras e quilombolas frente às instituições ${ }^{5}$.

Essa invisibilidade da população quilombola que se perpetua no âmbito das academias, pelo menos na área da saúde, é retratada na falta de publicações sobre esses grupos. Autores afirmam que, embora já se registre algum desenvolvimento nas pesquisas que focalizam a interface entre raça/cor e saúde, não existe suficiente produção acadêmica centrada nesta temática ${ }^{6}$.

(11) Enfermeira; Professora Orientadora do Grupo de Pesquisas Sobre Saúde das Populações Quilombolas do Norte de Minas Gerais - Universidade Estadual de Montes Claros Unimontes; Mestre em Ciências da Saúde.

(12) Acadêmico do Curso de Medicina da Unimontes; Jovem-Pesquisador do Grupo de Pesquisas Sobre Saúde das Populações Quilombolas do Norte de Minas Gerais - Universidade Estadual de Montes Claros - Unimontes.

(13) Médico; Professor Orientador do Grupo de Pesquisas Sobre Saúde das Populações Quilombolas do Norte de Minas Gerais - Universidade Estadual de Montes Claros Unimontes; Doutor em Ciências da Saúde.

Conflito de interesses: inexistente
O contexto nacional enseja, portanto, a inserção de estudantes da saúde nas pesquisas que abordem questões como iniquidades e recortes étnico-raciais. Esse estímulo pode interferir favoravelmente no desvelamento dos aspectos do racismo institucional e na promoção do debate universitário sobre o tema. O presente trabalho é parte de uma atividade de pesquisa e extensão desenvolvida no Norte de Minas Gerais com Comunidades Rurais Quilombolas. A região concentra $40 \%$ da população quilombola do estado, quase sempre segregadas a áreas rurais de difícil acesso. $O$ objetivo deste estudo foi verificar a percepção de estudantes da área da saúde sobre as condições de vida e saúde de Comunidades Quilombolas.

\section{MÉTODO}

Esta pesquisa foi aprovada pelo Comitê de Ética em Pesquisa da Unimontes com o Protocolo 076/2010.

Trata-se de uma pesquisa qualitativa realizada com estudantes da área de saúde que participaram de uma atividade de pesquisa e extensão em Comunidades Rurais Quilombolas do norte de Minas Gerais. Antes do início das atividades, os estudantes foram solicitados a completarem um diário de campo com o relato das atividades desenvolvidas durante a permanência nas comunidades e registro das percepções sobre o contato com a população local. Após a realização das atividades, os estudantes também participaram de um grupo focal onde foram apresentados temas sobre as percepções dos mesmos sobre as comunidades visitadas. A atividade do grupo focal foi gravada e depois as falas foram transcritas.

A interpretação do diário de campo e do grupo focal foi conduzida por meio da análise do conteúdo, após transcrição ${ }^{6}$.

Os diários de campo e o material gravado em vídeo registraram de forma complementar as percepções dos estudantes com incorporação da análise das falas informais, pausas e expressões faciais e corporais ${ }^{7}$.

\section{RESULTADOS}

Durante o processo de análise dos dados, as percepções dos estudantes foram categorizadas em três dimensões, a saber: reconhecimento das diferenças culturais, perplexidade com as condições precárias de vida e crescimento pessoal com a experiência. A seguir, essas dimensões serão apresentadas e comentadas a partir da análise realizada. 


\section{Reconhecimento das diferenças culturais}

Os estudantes destacaram marcadamente em seus registros um estranhamento positivo com relação à cultura local. Apontaram a receptividade e o acolhimento caloroso das comunidades como algo inusitado, assim como a habitual alegria de viver das comunidades visitadas.

"Observei que são muito acolhedores, nos recebiam sempre muito bem... Ofereciam o que tinham de melhor na casa deles". (E8)

"Recebem a gente muito bem. No dia do casamento a gente ficou assim... como convidados de honra". (E5)

"Parece que é uma questão cultural mesmo esse acolhimento deles e as condições de vida em comunhão que eles têm lá". (E1)

Alguns estudantes manifestaram sua surpresa ante ao preconceito provavelmente legado por familiares e amigos:

"No começo eu fiquei com medo... eu fui com medo, ouvia falar que eram perigosos... tinham facões..." (E6)

O sentido real da expressão 'comunidade' percebido nas atitudes das pessoas quilombolas foi também apontado pelos estudantes:

"Ele se organizam em uma sociedade que busca o melhor para todos... Eles se conhecem e isso facilita..." (E3)

"Eles são unidos e defendem a sua cultura..." (E7)

"Tem uma organização social que está melhorando as coisas para eles. Isso contribui para melhora da qualidade de vida. Eles lutam para isso". (E2)

Outros registros dos estudantes denunciam conflitos presentes nas comunidades, decorrentes de uma possível "invasão" de outras culturas.

"Eles defendem a sua cultura, mas a cidade vai até a comunidade e alguns possuem televisão..." (E1)

"Há pouco tempo não tinham problemas como o alcoolismo e drogas, mas essas coisas chegaram..." (E8)
"Parece que existem disputas entre a igreja católica e evangélica dentro da comunidade... Isso é assumido pelas pessoas... Não parece ser uma coisa de sempre, deles, mas é muito forte isso." (E4)

\section{Perplexidade com as condições precárias de vida}

Os estudantes registraram de forma bastante clara a surpresa com a realidade observada.

"Fiquei chocado com algumas coisas que vi... Em pleno século XXI saber que existem pessoas que vivem tão perto da civilização e em condições tão precárias... é de assustar" (E5)

"Me chamou atenção a disparidade de ver uma região muito pobre e tão perto da cidade. E perto da gente também... Nunca imaginei encontrar situação semelhante tão perto..." (E4)

"Em uma casa tinha nove pessoas vivendo com bolsa família... Tem muita pobreza, casas caindo e as pessoas dentro..." (E1)

É importante registrar que os olhares de surpresa dos estudantes foram especialmente direcionados às condições de saúde da população em questão:

"A saúde é muito ruim, muitas crianças com diarréia e mães novas, que casaram novas e seus filhos ficam largados... sujos... junto com os animais... uma mãe não sabia quem era o pai (do seu filho)... será que essas mães sabem como cuidar de suas crianças?' (E2)

\section{Crescimento pessoal com a experiência}

Unanimemente, os estudantes referiram um aprendizado importante para a vida pessoal e profissional, a partir das experiências vividas junto às comunidades quilombolas.

"Pessoalmente aprendi a lidar com as diferenças. Percebi que no início havia um distancia entre nós e o entrevistado, mas essa distância era provocada por nós. A partir do momento em que nós nos aproximamos e tivemos maior interação, a diferença desapareceu." (E3)

"A gente tem um crescimento pessoal grande... Só se a pessoa for muito fria, para não se sentir tocada, sensibilizada. Para a gente da área da saúde, só a oportunidade que tivemos... Fica um desejo de querer 
944 Freitas DA, Rabelo GL, Silveira JCS, Souza LR, Lima MC, Pereira MM, Moura PHT, Oliveira SKM, Siqueira Junior WR, Marques AS, Leão CDA, Macedo CP, Caldeira AP

ajudar o próximo... De querer ajudar mesmo." (E7)

"Me ensinou a dar mais valor em coisas pequenas, dar valor no que você tem..." (E2)

"Foi importante percebere comprovara importância da saúde básica. Profissionalmente, percebi que não basta o remédio... Na faculdade se dá muito valor às síndromes diferentes, mas as pessoas lá chegam com diarréia. Aquilo reflete muito boa parte do país..." (E1)

\section{DISCUSSÃO}

As Comunidades Rurais Quilombolas representam núcleos populacionais que se organizaram ao longo dos anos predominantemente em áreas rurais. Esse fato talvez justifique, parcialmente, a falta de interação desses grupos com os núcleos acadêmicos. A literatura registra que a interação de grupos quilombolas com as academias quase sempre ocorre por meio de atividades extensionistas e/ou da pesquisa. Foi nesse contexto que a Universidade Estadual de Montes Claros propiciou a alguns estudantes o contato com duas Comunidades Rurais Quilombolas, certificadas pela Fundação Palmares, em distritos do município de São Francisco, ao norte de Minas Gerais.

Reconhecimento das diferenças culturais

A definição de quilombola fundamenta-se, sobretudo, na auto-atribuição. Existe destaque ainda para a importância da trajetória histórica e para o processo de definição territorial, além da presunção de ancestralidade negra ${ }^{5,8}$. Não existe nenhuma referência às questões culturais no processo de reconhecimento de comunidades quilombolas e, de certa forma, esse aspecto se assenta no fato de que a opressão crônica impacta também sobre a cultura de um povo.

Seguramente as Comunidades Quilombolas não se mantiveram estáticas em suas tradições e aspectos culturais. Como comunidades que se comunicam com outras, os quilombolas estabelecem trocas interétnicas e interculturais ${ }^{9}$.

O registro acadêmico não apontou expectativas quanto a comportamentos tribais ou primitivos, mas observou o aspecto positivo de uma convivência harmoniosa, pacífica e acolhedora, que interage com os estranhos. É possível supor que os estudantes estivessem preparados para encontrar pessoas que, diante das dificuldades e limitações, fossem mais resistentes e avessos aos contatos com outras comunidades. De fato, os quilombolas enfrentam cotidianamente a tarefa de garantir a sua sobrevivência (e de sua família) e fortalecer a comunidade na luta contra o preconceito e a discriminação ${ }^{5,10}$. Essas dificuldades, todavia não se traduzem em relações hostis ou de rejeição, como se registraram comparativamente os estudantes em relação ao individualismo "branco" das cidades.

Os registros corroboram a discussão acerca da perda gradual da identidade quilombola. $\mathrm{Na}$ análise de alguns cientistas sociais, a partir da leitura das próprias comunidades quilombolas, "a identidade étnica nada tem de essencial"'. Mas, por outro lado, se não é possível estabelecer padrões culturais étnicos a partir de uma suposta ancestralidade negra, também não é possível deixar de reconhecer que tais comunidades se modificam a partir da invasão de territorial que não se limita às questões geográficas e incluem a massificação televisiva, o acesso às drogas e as disputas religiosas.

\section{Perplexidade com as condições precárias de vida}

Os registros denotam que as condições precárias de vida observadas superaram as expectativas dos estudantes e enfatizam o desconhecimento em relação às condições de vida da população quilombola no norte de Minas Gerais. Estudantes da área da saúde geralmente desenvolvem ações de interação com áreas periféricas das cidades, o que Ihes permitem conhecer a realidade dos pacientes que atendem. Esse contato, entretanto, não reflete as dimensões de vulnerabilidade que existem para as Comunidades Rurais Quilombolas visitadas.

De certo modo, essa percepção dos estudantes corrobora o conceito de racismo institucional, da discriminação e/ou percepção de estratificação social baseada na cor da pele ${ }^{11,12}$. Por outro lado, a perplexidade registrada reafirma a invisibilidade das condições de vida de muitas comunidades negras e quilombolas no País ${ }^{5}$. Essa percepção também descortina aspectos da relação entre identidade étnica e poder e pode favorecer a compreensão, por parte dos núcleos acadêmicos, de novas construções conceituais que facilitem o desenvolvimento de políticas públicas específicas ${ }^{13}$.

Como regra, a localização das comunidades quilombolas em áreas rurais reforça $o$ isolamento geográfico desses grupos. As desigualdades sociais e de saúde em que vivem são resultantes do processo histórico de submissão à ideologia dominante, com restrições e acessos diferenciados a bens e serviços o que se constitui, inclusive, em fatores condicionantes da situação de insegurança alimentar em que vivem essas pessoas ${ }^{14}$. Em verdade, as condições de vida de boa parte das comunidades quilombolas no país resultam das escassas fontes de subsistência, centradas nos recursos naturais, no restrito número de membros 
das comunidades (quase sempre isoladas) e no baixo desenvolvimento ou acesso aos bens tecnológicos ${ }^{9}$.

O reconhecimento legal das Comunidades Quilombolas foi oficialmente estabelecido a partir da Constituição de 1998 e desde então os aspectos referentes ao registro de tais comunidades estão sob a coordenação da Fundação Cultural Palmares ${ }^{8}$. Somente a partir do reconhecimento de tais comunidades, foram implantadas políticas de discriminação positiva na área dos direitos sociais e em saúde ${ }^{1}$.

Se por um lado, o prisma do olhar que emana dos estudantes destaca a compreensão da saúde como produto social, que se estende além dos limites biológicos, pode também denotar uma visão restrita à área de futura atuação profissional e negação do processo histórico de opressão e invisibilidade.

\section{Crescimento pessoal com a experiência}

Os apontamentos dos estudantes referendam as experiências de extensão acadêmica com imersão nos espaços comunitários. $\mathrm{Na}$ atividade desenvolvida, os estudantes assumiram um impacto positivo que vai desde a percepção do outro em suas condições restritas de sobrevivência até a revisão da importância dos temas acadêmicos.

Nenhum estudante referiu-se à questão étnico-racial ao descrever as percepções pessoais a partir da experiência. Não é possível saber por quais os motivos os estudantes não tocaram na questão étnico-racial ou não destacaram a cor da pele como item das considerações acerca das restrições sociais. Na área da saúde, os estudos nacionais habitualmente não se referem às questões étnico-raciais como determinantes das doenças. O histórico de miscigenação e o mito da "democracia racial" atuam como verdadeiros escudos às discussões na área e apenas nos últimos anos os trabalhos da saúde pública vem destacando a variável raça/cor como indicador de vulnerabilidade sócio-sanitária ${ }^{10}$. Todavia, a falta de padronização da variável e do seu modo de aferição também comprometem a definição de evidências para o setor saúde ${ }^{9}$. A invisibilidade (aos olhos dos estudantes) da negritude da população quilombola envolvida no estudo (em sua totalidade preta ou parda) é algo ainda a ser melhor abordado em análises futuras. A importância do recorte étnico/ racial, abordado por meio da cor da pele deveria merecer maior atenção das universidades, particularmente nos cursos da área da saúde. Destaque especial merece a interação entre as condições de vida da população negra e a susceptibilidade aos agravos à saúde, tanto pelos seus determinantes sociais como biológicos. Tais fatos não representam novidade no meio científico, já que estudos de natureza bibliográfica já detectaram a importância do conhecimento acerca do destacado e moderno assunto das populações quilombolas ${ }^{15}$.

\section{CONCLUSÃO}

As falas dos acadêmicos demonstram que os mesmos possuem grande sensibilidade social; entretanto, apontam para uma elevada incompreensão relativa às peculiaridades inerentes aos aspectos de saúde das populações quilombolas. $O$ estudo reafirma a necessidade premente de que os futuros profissionais de saúde sejam sempre confrontados com as realidades diversas e, às vezes, desiguais que se avolumam no Brasil.

\begin{abstract}
Purpose: to verify the perception of students about the conditions of life and health of Quilombo Communities. Method: it is a qualitative research with students of health field who participated in an activity of research and extension in Rural Communities Quilombola in northern Minas Gerais. We used data from Field Journal for Research, focus group interview, and the results analyzed through the prism of Content Analysis. Results: the perceptions of students were categorized into three dimensions: recognition of cultural differences, perplexity with the poor living conditions and personal growth through experience. The content analysis showed the importance of this activity for students of health. Conclusions: the study showed the amazement of the students on the aspects of inequality that people living north of the Maroons of Minas Gerais.
\end{abstract}

KEYWORDS: Health Vulnerability; Public Health; Ethnicity and Health; Brazil 


\section{REFERÊNCIAS}

1. Brasil. Ministério da Saúde. Secretaria-Executiva. Subsecretaria de Planejamento e Orçamento. A saúde da população negra e o SUS: ações afirmativas para avançar na equidade / Ministério da Saúde, Secretaria-Executiva, Subsecretaria de Planejamento e Orçamento. - Brasília: Editora do Ministério da Saúde, 2005.

2. Santos LM, Paes-Sousa R, Silva Junior JB, Victora CG. National Immunization Day: a strategy to monitor health and nutrition indicators. Bull World Health Organ. 2008;86(6):474-9.

3. Brasil. Ministério do Desenvolvimento Social e Combate à Fome. Conselho Nacional de Assistência Social. Relatório GT População Quilombola: Brasília; 2007.

4. Volochko A, Batista LE. Saude nos Quilombos. São Paulo: Instituto de Saúde - SESSP, Sao Paulo: GTAE - SESSP, 2009.

5. Santos GL, Chaves AM. Ser quilombola: representações sociais de habitantes de uma comunidade negra. Estudos de Psicologia. 2007;24(3):353-61.

6. Motta-Castro AR, Martins RM, Araujo NM, Niel C, Facholi GB, Lago BV, et al. Molecular epidemiology of hepatitis $B$ virus in an isolated Afro-Brazilian community. Arch Virol. 2008;153(12):2197-205.

7. Fontanella BJB, Ricas J, Turato ER. Amostragem por saturação em pesquisas qualitativas em saúde: contribuições teóricas. Cad. Saúde Públ. 2008;24(1):17-27.
8. Rodrigues E. Plants of restricted use indicated by three cultures in Brazil (Caboclo-river dweller, Indian and Quilombola). J Ethnopharmacol. 2007; 4;111(2):295-302.

9. Brandão A, Dalt A, Gouveia VH. Comunidades quilombolas no Brasil: características socioeconômicas, processos de etnogênese e políticas sociais. Editora da UFF. Niteroi, 2010.

10. Araújo EM, Costa MCN, Hogan VK, Araújo TM, Dias AB, Oliveira LOA. A utilização da variável raça/ cor em Saúde Pública: possibilidades e limites. Interface. 2009;13(31):383-94.

11. Onocko CRT, Furtado JP. Narrativas: utilização na pesquisa qualitativa em saúde. Rev. Saúde Públ. 2008;42(6):1090-6.

12. Travassos C, Williams DR. The concept and measurement of race and their relationship to public health: a review focused on Brazil and the United States. Cad. Saúde Pública. 2004;20(3):660-78.

13. Calheiros FP, Stadler HHC. Identidade étnica e poder: os quilombos nas políticas públicas brasileiras. Rev. Katál. 2010;13(1):133-9.

14. Silva DO, Guerrero AFH, Guerrero $\mathrm{CH}$, Toledo LM. A rede de causalidade da insegurança alimentar e nutricional de comunidades quilombolas com a construção da rodovia BR-163, Pará, Brasil. Rev. Nutr. 2008;21(suppl. 0):83s-7s.

15. Freitas $D A$, Caballero $A D$, Marques $A S$, Hernández CIVergara, Antunes SLNO. Saúde e comunidades quilombolas: uma revisão da literatura. Rev. CEFAC. 2011;13(5):937-43.

Recebido em: 01/05/2012

Aceito em: 26/03/2013

Endereço para correspondência:

Daniel Antunes Freitas

Faculdades Unidas do Norte de Minas

- FUNORTE

Avenida Osmane Brandao, s/n - Bairro JK

Montes Claros - MG

CEP: 39400-000

E-mail: danielmestradounincor@yahoo.com.br 